\title{
Energia eólica: desenvolvimento de geração de energia sustentável
}

O presente estudo teve como objetivo identificar como produzir energia elétrica sustentável a partir da fonte de energia eólica. Para tanto, a metodologia quanto ao objetivo foi uma pesquisa exploratória, quanto ao procedimento este estudo foi desenvolvido com base na pesquisa bibliográfica, e, em relação à abordagem foi uma pesquisa do tipo qualitativa. Portanto, o trabalho em tela demonstrou as etapas necessárias para implantação de um parque eólico, iniciando-se com a definição da área de instalação e análise do potencial eólico desse local (identificar a potência do vento, o aproveitamento da potência instalada em um parque eólico e a previsão de ventos e de geração eólica de energia). Logo após segue-se para a elaboração do projeto de Micrositing. Posteriormente é feita a escolha do aerogerador, visto que a quantidade de energia produzida por uma turbina varia de acordo com o tamanho das suas hélices e com o regime de ventos da região. A próxima etapa é a aprovação do projeto, sendo a instalação dos equipamentos necessários ao seu funcionamento realizada pela empresa responsável pelo parque. Diante do que foi exposto, percebeu-se a importância do aumento de participação de fontes renováveis de geração de energia elétrica, entre elas, a eólica. Buscou-se demonstrar a importância da geração de energia elétrica através da fonte de energia eólica, visto que o Brasil ainda produz pouca energia a partir desta fonte, apesar de possuir um vasto território com um vasto potencial para a produção da mesma.

Palavras-chave: Desenvolvimento Sustentável; Energia Renovável; Energia Eólica.

\section{Wind energy: development of generation of sustainable energy}

\begin{abstract}
The present study aimed to identify how to produce sustainable electricity from wind energy source. Therefore, the methodology used as the objective was exploratory, as the procedure was literature and, in relation to the approach was qualitative. Thus, the work on the screen demonstrates the steps necessary to implement a wind farm, starting with the definition of the area of installation and analysis of the wind potential of this location (identify wind power, use of installed power in a wind farm and forecast wind and wind power generation). Soon after, it is followed for the elaboration of the project of Micrositing. Subsequently the choice of wind turbine is made, since the amount of energy produced by a turbine varies according to the size of its propellers and the region's wind regime. The next step is the approval of the project, being the installation of the necessary equipment for its operation carried out by the company responsible for the park. In view of the above, it was noticed the importance of increasing the participation of renewable sources of electric power generation, among them, wind power. It was tried to demonstrate the importance of the generation of electric energy through the source of wind energy, since Brazil still produces little energy from this source, despite having a vast territory with a vast potential for its production.
\end{abstract}

Keywords: Sustainable Development; Renewable Energy; Wind Energy.

\section{Topic: Sistemas de Energia Sustentável}

Reviewed anonymously in the process of blind peer.
Received: 10/10/2016

Approved: 05/01/2017
Denis Bellini

denis.bellini@yahoo.com.br

Elyrouse Cavalcante de Oliveira

Universidade Federal de Alagoas, Brasil.

http://lattes.cnpq.br/2523512608621919

elyrouse@gmail.com

Umbelina Cravo Teixeira Lagioia

Universidade Federal de Pernambuco, Brasil.

http://lattes.cnpq.br/3533446028459118

umbelina@ufpe.br

\author{
Alexandre César Batista da Silva \\ Universidade Federal de Pernambuco, Brasil. \\ http://lattes.cnpq.br/8320643857508960 \\ acbspe@uol.com.br \\ Jefferson Lisboa Melo \\ Pontifícia Universidade Católica de São Paulo, Brasil. \\ http://lattes.cnpq.br/3011040478071802 \\ jeffersonmelo@gmail.com
}

\section{Referencing this:}

BELLINI, D.; OLIVEIRA, E. C.; LOGIOIA, U. C. T.; SILVA, A. C. B.; MELO, J. L.. Energia eólica: desenvolvimento de geração de energia sustentável. Revista Ibero-Americana de Ciências Ambientais, v.8, n.2, p.205-223, 2017. DOI: http://doi.org/10.6008/SPC21796858.2017.002.0017 


\section{INTRODUÇÃO}

Não há como não perceber as degradações que o meio ambiente está passando com o passar dos anos, principalmente com o aumento populacional, as necessidades de recursos naturais, território limitado, além da conscientização precária da sociedade. As interferências desordenadas feitas ou realizadas pelo homem são um problema antigo, mas somente na atualidade está sendo debatido, a fim de procurar soluções ou ao menos amenizar os problemas causados por antigas gerações, quase vistos sem soluções. Nesse contexto surge o desenvolvimento sustentável, com o objetivo de promover o crescimento econômico aliado à preservação do meio ambiente (NAGATA et al., 2010).

Segundo Rosa (2007), devido a questões ambientais e do desenvolvimento sustentável, mais notadamente no período que compreende a Rio-92 (Conferência das Nações Unidas para o Meio Ambiente e Desenvolvimento - CNUMAD) e a Rio+10 (Cúpula Mundial sobre Desenvolvimento Sustentável na África do Sul), houve uma intensificação de movimentos a favor de uma maior participação de fontes de energias renováveis alternativas na matriz energética brasileira, iniciando-se com o surgimento de centros de referência em energia eólica e solar (1994), de biomassa (1996) e de pequenas centrais hidrelétricas (PCH1997), culminando, em 2002, com a criação do Programa de Incentivo às Fontes Alternativas de Energia Elétrica (PROINFA).

Nos tempos atuais, busca-se responder aos desafios criados pelas alterações climáticas e reduzir a dependência de combustíveis fósseis, visto que as evoluções da tecnologia, econômica e social estão relacionadas com a utilização dos mesmos e, o seu uso de forma indiscriminada tem acarretado na deterioração ambiental (LOPES, 2009).

Diante do exposto, é importante tratar de formas de produção de energia renováveis como uma alternativa a fontes de energia esgotáveis derivados de combustíveis sólidos como o petróleo, o carvão e o gás natural, entre elas, estão a energia eólica, fonte de energia gratuita, que é objeto de estudo deste trabalho. A partir do que foi exposto nas considerações iniciais, surge o seguinte questionamento: Como produzir energia elétrica sustentável a partir da fonte de energia eólica?

Contudo, a presente pesquisa tem como objetivo geral, identificar como produzir energia elétrica sustentável a partir da fonte de energia eólica. Para se proceder à consecução do objetivo geral do trabalho alguns passos são necessários, onde se destacam os seguintes objetivos específicos: identificar, na legislação e na literatura especializada, os marcos conceituais referentes a fontes de energias renováveis e sustentáveis, seus impactos ambientais e econômicos e sobre desenvolvimento sustentável; Contextualizar a produção de energia eólica no Brasil e no mundo; Demonstrar as etapas para a geração de energia eólica; Identificar como produzir energia elétrica a partir da fonte de energia eólica com o objetivo de dar sustentação ao delineamento da investigação pretendida.

Esse trabalho justifica-se à medida que busca demonstrar a comunidade acadêmica e a sociedade em geral a importância do uso da energia eólica como fonte de energia alternativa às energias não renováveis, as quais são esgotáveis e escassas. 
Quanto à natureza esta é uma pesquisa aplicada, pois busca gerar conhecimentos sem aplicação prática. Procurou-se, também, nesta seção delinear os procedimentos da pesquisa na tipologia recomendada por Beuren (2008): Quanto ao objetivo, foi uma pesquisa exploratória, buscando conhecer com maior profundidade o assunto sobre energias renováveis e sustentáveis de modo a torná-lo mais claro; Quanto ao procedimento este estudo foi desenvolvido com base na pesquisa bibliográfica, através de sites, livros e artigos e em relação à abordagem foi uma pesquisa do tipo qualitativa.

\section{DISCUSSÃO TEÓRICA}

\section{Desenvolvimento Sustentável}

A origem do conceito de desenvolvimento sustentável surgiu a partir de estudos da Organização das Nações Unidas (ONU) acerca das mudanças climáticas, em resposta à crise social e mundial na segunda metade do século XX (BARBOSA, 2008).

Foi na Comissão Mundial para o Meio Ambiente e Desenvolvimento (CMMAD), também conhecida como Comissão de Brundtland, presidida pela norueguesa Gro Haalen Brundtland, no processo preparatório a Conferência das Nações Unidas - também chamada de "Rio 92", que surgiu o Relatório Brundtland, publicado em 1987, intitulado Nosso Futuro Comum, o qual foi baseado no princípio de que o ser humano deve usufruir dos recursos naturais de acordo com a capacidade de renovação dos mesmos, evitando o seu esgotamento (NAGATA et al., 2010; BARBOSA, 2008).

Um dos conceitos mais difundidos de desenvolvimento sustentável está no relatório Brundtland que diz que "o desenvolvimento sustentável é aquele que atende as necessidades do presente sem comprometer as possibilidades de as gerações futuras atenderem suas próprias necessidades" (CMMAD, 1991).

As práticas de desenvolvimento sustentáveis foram firmadas na Conferência Rio 92, também conhecida como ECO-92, na qual após inúmeras análises culminaram no desenvolvimento de documentos, nos quais constam a Carta da Terra e a Agenda 21 que expõe a situação atual do planeta e o que a humanidade deve fazer para continuar crescendo, mas de maneira consciente (NAGATA et al., 2010).

\section{Energias Renováveis}

As energias renováveis aparecem como alternativas para reduzir os efeitos da crise acarretada pelas mudanças climáticas derivadas de emissões dos gases de efeito estufa os quais acarretaram uma crise ambiental planetária sem precedentes. Ao mesmo tempo, não é possível prever se essa alternativa será capaz de substituir a energia fóssil futuramente BERMANN (2008). Tanto no contexto internacional como no Brasil, tem havido esforços para ampliação da utilização das energias renováveis. Segundo Bernann (2008):

As fontes alternativas de energia como eólica, solar e biomassa, são consideradas de forma positiva. Além de causarem impactos substancialmente menores, ainda evitam a emissão de toneladas de gás carbônico na atmosfera. O debate contínuo, sobre os impactos causados pela dependência de combustíveis fósseis, contribui decisivamente para o interesse mundial por soluções sustentáveis por meio de geração de energia oriunda de fontes limpas e renováveis, e ambientalmente corretas. 
Segundo Rosa (2007), devido a questões ambientais e do desenvolvimento sustentável, mais notadamente no período que compreende a Rio-92 (Conferência das Nações Unidas para o Meio Ambiente e Desenvolvimento - CNUMAD) e a Rio+10 (Cúpula Mundial sobre Desenvolvimento Sustentável na África do Sul), houve uma intensificação de movimentos a favor de uma maior participação de fontes de energias renováveis alternativas na matriz energética brasileira, iniciando-se com o surgimento de centros de referência em energia eólica e solar (1994), de biomassa (1996) e de pequenas centrais hidrelétricas (PCH1997), culminando, em 2002, com a criação do Programa de Incentivo às Fontes Alternativas de Energia Elétrica (PROINFA).

O PROINFA foi criado em 26 de abril de 2002, pela Lei no 10.438, e revisado pela Lei no 10.762, de 11 de novembro de 2003, assegurando a participação de um maior número de estados no programa, o incentivo à indústria nacional e a exclusão dos consumidores de baixa renda do rateio da compra da nova energia e o seu principal objetivo é financiar, com o auxílio do Banco Nacional de Desenvolvimento Social (BNDES), projetos de geração de energias a partir dos ventos (energia eólica), Pequenas Centrais Hidrelétricas (PCHs) e bagaço de cana, casca de arroz, cavaco de madeira e biogás de aterro sanitário (biomassa) (BERNANN, 2008).

\section{Energia Eólica}

O termo eólico deriva do latim aeolicus, pertencente ou relativo a éolo, que na mitologia grega é o deus dos ventos, portanto, pertencente ou relativo ao vento, podendo este ser definido como deslocamentos de massas de ar resultantes das diferenças de aquecimento da Terra pela radiação solar, constituindo, indiretamente, uma forma de energia solar representando o resultado da transformação de energia térmica em cinética, sendo o aproveitamento da energia dos ventos chamada de energia eólica (BARBOSA, 2008). Para Bermann (2008):

A energia dos ventos pode ser explicada, em termos físicos, como aquela de origem cinética formada nas massas de ar em movimento". Seu aproveitamento é feito por meio de conversão da energia cinética de translação, em energia cinética de rotação. Para a produção de energia eólica, são utilizadas turbinas também conhecidas como aerogeradores, e para a realização de trabalhos mecânicos (como bombeamento de água ou a moagem do trigo), cata-ventos de diversos tipos.

Segundo Dalmaz et al. (2008), a milhares de anos a energia dos ventos tem sido utilizada para produzir trabalho, como movimentar embarcações, moer grãos, através dos moinhos de vento, bombear água, movimentar serrarias, entre outras aplicações.

Conforme Sektorov (1994, citado por LOPES, 2009) foi na Rússia, em 1931, que foram dados os primeiros passos para o desenvolvimento de turbinas eólicas de grande porte para aplicações eléctricas, com a primeira tentativa de ligar um aerogerador de corrente alternada a uma central termoeléctrica, o qual foi designado de Balaclava, um modelo avançado de $100 \mathrm{~kW}$ conectado por uma linha de transmissão de 6,3 kV de $30 \mathrm{~km}$ a uma central de $20 \mathrm{MW}$. Mas, foi a segunda guerra mundial ((1939-1945) quem contribuiu para o desenvolvimento dos aerogeradores de médio e grande porte, visto que os países se esforçavam para 
economizar combustíveis fósseis. Nesse período, os Estados unidos (EUA) projetaram o maior aerogerador até então projetado denominado Smith-Putnam cujo modelo tinha $53.3 \mathrm{~m}$ de diâmetro, uma torre de 33.5 $\mathrm{m}$ de altura e duas pás de aço com 16 toneladas, tendo o início de seu funcionamento em 10 de Outubro de 1941, numa colina de Vermont chamada Grandpa's Knob, e após quatro anos de operação intermitente, em março de 1945, uma das suas pás (que eram metálicas) partiu-se por fadiga.

Um dos mais significativos crescimentos em energia eólica da Europa ocorreu na Dinamarca, ainda no período da segunda guerra mundial, sob o comando dos cientistas dinamarqueses Poul LaCour e Johannes Juul. Diversos aerogeradores de grande porte foram construídos também na França entre 1958 e 1966, entre eles, estavam três aerogeradores de eixo horizontal e três pás. Mas, foi a Alemanha que construiu e operou, entre 1955 e 1968, um aerogerador com o maior número de inovações tecnológicas da época. Os avanços tecnológicos desse modelo persistem até hoje na concepção dos modelos atuais mostrando o seu sucesso de operação. Era um aerogerador de 34 metros de diâmetro operando com potência de 100kW, a ventos de 8m/s (JUL, 1994; GASH et al., 2002; BUNNEFILLE, 1994; HUTTER, 1994; CASTRO, 2003 citado por LOPES, 2009).

Um grande desafio da humanidade é suprir a demanda de energia sem agredir o meio ambiente, sendo a geração de energia eólica uma importante forma de minimizar esse problema, pois a mesma é uma fonte de energia renovável, abundante e limpa, a qual é originada na própria dinâmica da atmosfera terrestre, ou seja, a força dos ventos surge da diferença no aquecimento da superfície terrestre pelo Sol. Entretanto, a origem dessa forma de geração de energia possui problemas que dificultam a sua integração à rede elétrica, visto que depende das condições atmosféricas, sendo de difícil previsão a quantidade de energia que será gerada, já que as condições do vento não podem ser controladas (DALMAZ et al., 2008).

O choque petrolífero de 1973, acentuou a necessidade de assegurar a diversidade e segurança no fornecimento de energia, bem como a obrigação de proteger o ambiente, motivando um maior interesse pelas energias renováveis. A energia eólica tornava-se assim numa fonte de energia das mais promissoras, desenrolando-se programas de investigação e desenvolvimento sobre estas. (LOPES, 2009)

De acordo com Lopes (2009) foi em 1973, nos EUA, que se iniciou o programa de energia eólica que após dois anos culminou com a instalação da primeira turbina eólica da era moderna perto de Cleveland, Ohio, a Mod 0, com um rotor de duas pás com 38 metros de diâmetro e $100 \mathrm{~kW}$ de potência. $\mathrm{O}$ próximo passo dado pelos EUA no desenvolvimento de turbinas de grandes dimensões foi em $1981 \mathrm{com}$ a instalação da turbina Boeing Mod 2 de 91 metros de diâmetro e 2,5MW de potência, incorporando os mais recentes progressos tecnológicos. Formando, nesse período, os consórcios entre empresas americanas e europeias, mais concretamente suecas e americanas, em programas de investigação e desenvolvimento de turbinas de grande potência, como exemplo desta cooperação estão as turbinas americano-suecas WTS3 (3MW) e WTS (4MW) instaladas em 1982 (MUSGROVE, 1990, citado por LOPES, 2009).

As primeiras turbinas eólicas comerciais foram instaladas no início dos anos 80, tanto na Europa (principalmente na Dinamarca e Holanda) como nos E.U.A. (em particular na Califórnia), tendo tipicamente entre 10 a 20 metros de diâmetro e potências de 50 a 100 kW. O rápido desenvolvimento de parques eólicos 
financiados por entidades privadas deveu-se, principalmente, à política de incentivo à disseminação de energias renováveis promovida pelo estado da Califórnia, devido à grande velocidade do vento de alguns locais deste estado.

Em 1987, a potência instalada em sistemas de conversão de energia eólica era de $1500 \mathrm{MW}$ fornecidos por cerca de 15000 turbinas eólicas, a maior parte delas com diâmetros entre 15 a 25 metros (CASTRO, 2003). “A positiva experiência de operação com turbinas maiores, em conjunto com os frutos dos programas de investigação, levaram a que o tamanho das turbinas eólicas comerciais não tenha parado de crescer" (LOPES, 2009).

Após a primeira crise do petróleo, na década de 70, houve um grande impulso à geração de energia eólica, com vários países investindo em pesquisas sobre novas formas de energia, destacando-se os estudos de energia elétrica, especialmente na Alemanha, Dinamarca, EUA e Espanha. (DALMAZ et al., 2008). Para Simas et al. (2013), os diversos países na época buscavam a segurança no fornecimento de energia e a redução da dependência da importação de combustíveis e, mais recentemente, a busca de alternativas de produção de energia limpa são as preocupações ambientais.

Nesse sentido, preocupações com as mudanças climáticas e esforços para a redução das emissões de Gases de Efeito Estufa (GEE), com a assinatura do Protocolo de Quioto, em 1997, acentuaram a procura de alternativas capazes de suprir as necessidades econômicas e que pudessem causar menos impactos ao meio ambiente, como as fontes energia renováveis, a exemplo da energia eólica.

Conforme o Painel Intergovernamental para Mudanças Climáticas (IPCC, 2011), a fonte de energia eólica oferece um grande potencial para a redução das emissões de gases de GEE. Apesar do potencial técnico de energia eólica não ser distribuído uniformemente entre os países do mundo ele é maior que a produção mundial de energia elétrica e levando-se em consideração barreiras políticas, econômicas e tecnológicas, estima-se que ela poderia suprir até $20 \%$ da demanda mundial de energia elétrica até 2050.

Os altos custos iniciais e o estágio de desenvolvimento dessa tecnologia em relação às tecnologias tradicionais disponíveis no mercado, no entanto, conferiam à energia eólica uma característica de baixa competitividade. As barreiras técnicas e econômicas levaram à necessidade de incentivos econômicos e regulatórios, o que levou à adoção de políticas de apoio às energias renováveis em diversos países. Em 2005, apenas 55 países adotavam algum tipo de incentivo às fontes renováveis, enquanto no início de 2011 tais políticas estavam presentes em 118 países (REN21, 2011, citado por SIMAS et al., 2013). Apesar dos custos de instalação de energia eólica ainda serem altos, os mesmos vêm diminuindo ao longo do tempo devido os avanços tecnológicos e de planejamento dos projetos dos parques eólicos. Na Europa o custo de instalação de um parque eólico é um pouco maior a US\$ 1000 / kW, enquanto no Brasil os valores chegam a custar, em torno de R\$ 3500 / kW instalado, conforme relatado por Jens P. Molly do Instituto Alemão de Energia Eólica (DEWI) em 2005 (DALMAZ et al., 2008).

Devido os incentivos para a adoção de energia eólica, houve um aumento de participação de diversos países a partir de 1996, sendo acentuado em 2004 com o Programa de Incentivo às Fontes Alternativas de Energia Elétrica (PROINFA). A capacidade eólica em operação no mundo chegou a 238 GW (GWEC, 2012) em 
2011. Entretanto, com a crise financeira de 2008, o mercado de energia eólica desaqueceu na Europa e nos Estados Unidos, principais mercados para essa tecnologia, fazendo com que grandes empresas diversificassem a sua atuação, realizando investimentos em mercados emergentes, a exemplo do Brasil (SIMAS et al., 2013).

Na América Latina o Brasil foi pioneiro no início da década de 1990, mais precisamente em 1992, na instalação de um aerogerador. Devido à falta de políticas e do alto custo tecnológico, nos próximos dez anos pouco se avançou em geração de energia eólica. Em 2001 foi lançado o Atlas do Potencial Eólico Brasileiro, que estimou em $143 \mathrm{GW}$ a potência tecnicamente aproveitável do Brasil (CEPEL, 2001).

Segundo o inventário, cerca de $90 \%$ de todo o potencial eólico do Brasil encontra-se na Região Nordeste, Sul e Sudeste, entretanto, o referido estudo encontra-se defasado por utilizar medições de vento na altura da tecnologia de aerogeradores corrente à época, de 50 metros de altura. Atualmente, são utilizados aerogeradores com torres de 80 a 100 metros de altura, além de máquinas mais eficientes, e estudos mais recentes da indústria e do governo estimam em cerca de $300 \mathrm{GW}$ o potencial de aproveitamento do recurso eólico no Brasil (SIMAS et al., 2013). Para Dalmaz et al. (2008) destacam-se no Brasil o litoral do nordeste, principalmente do Ceará e do Rio Grande do Norte, o litoral do Rio Grande do Sul, as Serras Gaúcha e Catarinense, alguns locais do litoral Catarinense e a região dos campos entre Paraná e Santa Catarina. Em relação ao nordeste, dados de vento mostram áreas com médias anuais de velocidades superiores a 8,5 m/s. A CHESF (Companhia Hidroelétrica do São Francisco) e a COPEL (Companhia Paranaense de Energia) realizaram estudos que demonstram que, para certas regiões, há complementaridade entre a geração hídrica e a eólica, ou seja, os períodos do ano com maior incidência de ventos coincidem com os de menor oferta de chuvas.

Uma das matrizes elétricas mais renováveis no mundo está no Brasil. Em 2012, mais especificamente no início do segundo trimestre, a capacidade de geração de energia de fontes renováveis correspondia a 79,3\%, com mais de 70\% devido a hidrelétricas. Em 2011 o potencial de usinas hidrelétricas correspondia a mais de $90 \%$ da geração de eletricidade no país, além da importação de eletricidade de usinas binacionais ou de países vizinhos (DALMAZ et al., 2008).

Além do grande potencial eólico inexplorado no país e localizado, muitas vezes, em áreas de baixa densidade demográfica, a energia eólica possui ainda uma vantagem em relação ao sistema elétrico brasileiro. A expansão territorial brasileira e seu sistema interligado, predominantemente baseado em hidrelétricas, conferem ao Brasil uma característica de maior sustentabilidade ambiental à energia eólica. Devido ao seu caráter intermitente, essa tecnologia deve ser compensada com usinas elétricas flexíveis, geralmente termelétricas, reduzindo o potencial de redução de emissões de gases de efeito estufa dessa fonte. No Brasil, no entanto, há a possibilidade de combinação das usinas hídricas e eólicas, criando um sistema com maior confiabilidade, uma vez que a energia eólica gerada poderá ser estocada nos reservatórios hidrelétricos, aumentando assim o fator de capacidade das usinas hidrelétricas e dispensando a ativação de termelétricas. Esse fato é ainda mais relevante sendo a geração eólica no Brasil maior no período de menor volume dos reservatórios. No Brasil, um sistema hidroeólico seria capaz de suprir toda a demanda de energia elétrica futura da população brasileira (CARVALHO, 2012, citado por SIMAS et al., 2013). 
O Programa de incentivo às Fontes Alternativas de Energia Elétrica (PROINFA), criado em 2002, foi um importante programa de incentivo para impulsionar o desenvolvimento do mercado eólico Brasileiro, através de financiamentos e garantias de compra e preço de energia, buscando aumentar a participação das fontes alternativas na matriz energética no Brasil (DALMAZ et al., 2008). Foi a primeira política pública voltada ao setor de energia elétrica, o qual proporcionou um ambiente de baixos riscos para o investimento nessa nova tecnologia, além de demonstrar a viabilidade técnica da energia eólica. $\mathrm{O}$ ambiente tornou-se mais atrativo ainda para os investidores com contratos de longo prazo de compra de energia pela Eletrobrás a uma tarifa que refletisse os custos de capital, as condições de financiamento pelo BNDES de até $80 \%$ do projeto e a flexibilidade de geração (SIMAS et al., 2013). Desde 2009, a entrada da energia eólica no mercado regulado de energia como parte da política de diversificação da matriz elétrica e de contratação prioritária de fontes renováveis, acarretou em um novo marco para a inserção dessa tecnologia no setor elétrico brasileiro.

Ao Conselho Nacional de Política Energética - CNPE compete o estabelecimento de políticas e diretrizes, visando ao desenvolvimento nacional sustentado. As funções de planejamento são exercidas pelo Estado Brasileiro, na forma da lei, o qual é determinante para o setor público e indicativo para o setor privado, tendo como uma das principais fontes de planejamento de expansão eletro energética do país, os Planos Decenais de Expansão de Energia - PDE, elaborados no setor elétrico, os quais desde 2007 tiveram a abrangência de seus estudos, introduzindo uma visão integrada da expansão da demanda e da oferta de diversos energéticos, além da energia elétrica.

A capacidade instalada total do sistema elétrico brasileiro no final de 2014 era de, aproximadamente, 134 mil MW, conforme dados do Banco de Informações de Geração da ANEEL - BIG, incluindo nesse total as unidades geradoras do SIN, mas também aquelas instaladas nos sistemas isolados e a autoprodução clássica, não contabilizando a parcela de importação da UHE Itaipu (EPE, 2015).

O PDE 2022 e 2023 teve como principal diretriz a priorização da participação das fontes renováveis para atender ao crescimento do consumo de energia elétrica no horizonte decenal, tendo em vista o compromisso brasileiro para redução da emissão de gases de efeito estufa, estabelecido na Lei no 12.187 de 29/12/2009 e regulamentado por meio do Decreto no 7.390 de 09/12/2010, dando continuidade a esses objetivos, o PDE 2024 traz importantes sinalizações para orientar as ações e decisões, relacionadas ao equilíbrio entre as projeções de crescimento econômico do país e a necessária expansão da oferta, visando garantir à sociedade o suprimento energético com adequados custos, em bases técnica e ambientalmente sustentável, destacando-se a previsão da continuidade da forte presença das fontes renováveis na matriz energética brasileira, de $45,2 \%$ em 2024 , indicador superior ao verificado em 2014 , de $39,4 \%$. As energias renováveis deverão representar perto de $86 \%$ em 2024, na matriz de geração de energia elétrica superando a atual predominância destas fontes, vale ressaltar, o crescimento da energia eólica, que dos atuais $2 \%$ da matriz elétrica deverá passar a $8 \%$ em 2024, devido à expansão de 20 GW no período. Percebe-se que há um indicativo de um processo de diversificação da matriz de energia elétrica, que embora predominantemente energia hidráulica, verifica-se um crescimento expressivo de outras fontes renováveis (EPE, 2015). 
Segundo o PDE 2024, a expansão eólica prevê 18.909 MW de potência, distribuídos no Nordeste e Sul do Brasil, sendo prevista a maior parte dessa energia ser instalada nos primeiros cinco anos do horizonte decenal (10.909 MW). O Nordeste vai agregar a maior quantidade de MW instalados com 9.297 MW e a região Sul está prevista a instalação de $1.351 \mathrm{MW}$.

A análise socioambiental da expansão da transmissão neste PDE 2024 considera o conjunto de linhas de transmissão (LTs) da rede básica (tensão igual ou superior a 230 kV) previsto para entrar em operação nos próximos 10 anos. Em razão da escala de análise, não foram consideradas LTs com extensão inferior a $10 \mathrm{~km}$ e projetos de recapacitação e recondutoramento. Dessa forma, a expansão aqui compreende, no horizonte decenal, 267 novas LTs a serem agregadas ao SIN, que perfazem uma extensão de aproximadamente 46.000 km. Desse conjunto de empreendimentos, 250 (mais de 90\%), estão previstos para entrar em operação até 2019, ou seja, no primeiro quinquênio do horizonte decenal, dos quais metade já foram licitados.

Ainda segundo o PDE 2024, O incremento médio anual da carga de energia elétrica no SIN (já incorporados os ganhos de eficiência energética e desconsiderando-se a parcela da autoprodução) será de, aproximadamente, 2.900 MWmed no período 2015-2024, respondendo deste montante os subsistemas Sul, Sudeste/Centro-Oeste e Acre/Rondônia por 71\%, ou, aproximadamente, $2.050 \mathrm{MWmed}$ ao ano, e os subsistemas Norte, Nordeste e Manaus/Amapá/Boa Vista crescem, em média, 850 MWmed ao ano neste período, representando $29 \%$.

A expansão da geração no horizonte decenal incorpora os resultados dos leilões de compra de energia elétrica promovidos até abril de 2015, resultando em uma configuração de expansão parcialmente definida a priori. A data de entrada em operação desses empreendimentos, considerada neste plano, é atualizada de acordo com as reuniões de acompanhamento do Comitê de Monitoramento do Setor Elétrico - CMSE38. De modo a garantir as condições de atendimento em todo o horizonte decenal, a oferta indicativa leva em consideração os prazos estimados para entrada em operação das usinas contratadas nos leilões futuros, além da necessidade energética, completando assim a configuração de expansão do cenário de referência (EPE, 2015).

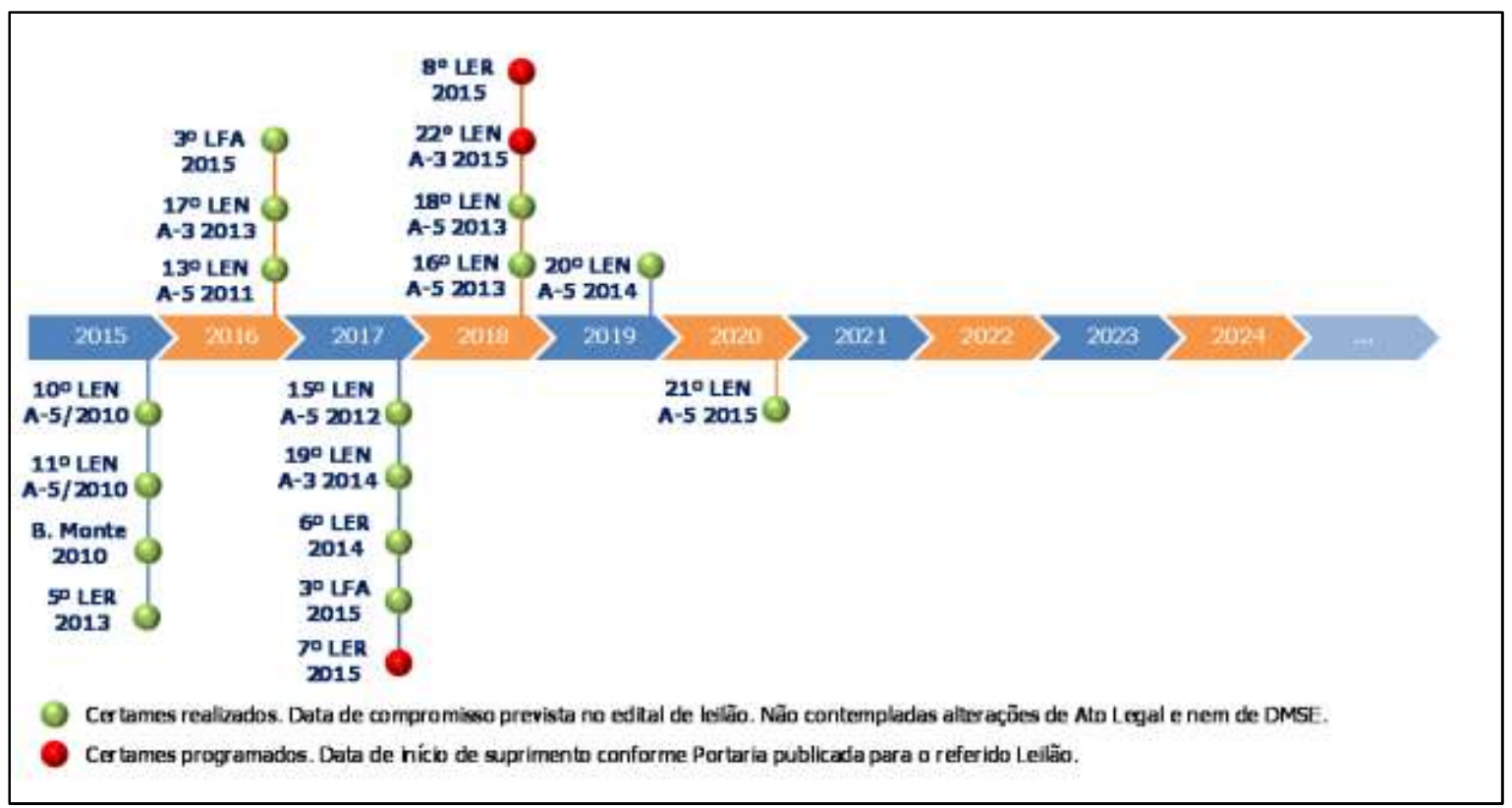

Figura 1: Leilões que contrataram energia para início de suprimento previsto no horizonte do PDE 2024 e aqueles já programados. Fonte: EPE (2015). 
A Figura 01 demonstra os leilões que contrataram energia para início de suprimento previsto no horizonte do PDE 2024 e aqueles já programados, conforme portaria publicada, que ocorreram em 2015. Salienta-se que, considerando as datas de compromisso de entrega de energia previstas nos leilões, não há oferta contratada para início de suprimento após 2021, fazendo com que nesses anos finais a expansão seja totalmente indicativa

Houve uma expansão de fontes renováveis (eólicas, PCH, termelétricas a biomassa e solar) média anual de $10 \%$, em percentual da capacidade instalada total dessas fontes, contribuindo a Região Nordeste com a maior participação na expansão dessas fontes no período em análise, conforme gráfico posterior. Os projetos que têm seus estudos e processos de construção e licitatórios acompanhados, fiscalizados e sinalizados como "verde" (Empreendimentos para os quais não existem impedimentos para entrada em operação (contrato de concessão assinado, licença ambiental de instalação vigente e obras civis iniciadas e não interrompidas) pela ANEEL estão representados na expansão contratada (EPE, 2015).

Dentre as fontes renováveis a energia eólica é a que mais cresceu em participação nos leilões desde 2009 e as contratações dos últimos anos mostram que as usinas eólicas atingiram preços bastante competitivos e impulsionaram a instalação de uma indústria nacional de equipamentos para atendimento a esse mercado e essa crescente participação na matriz de energia elétrica foi o resultado de vários fatores relacionados ao cenário externo, ao desenvolvimento tecnológico e da cadeia produtiva, além de aspectos regulatórios, tributários e financeiros (EPE, 2015).

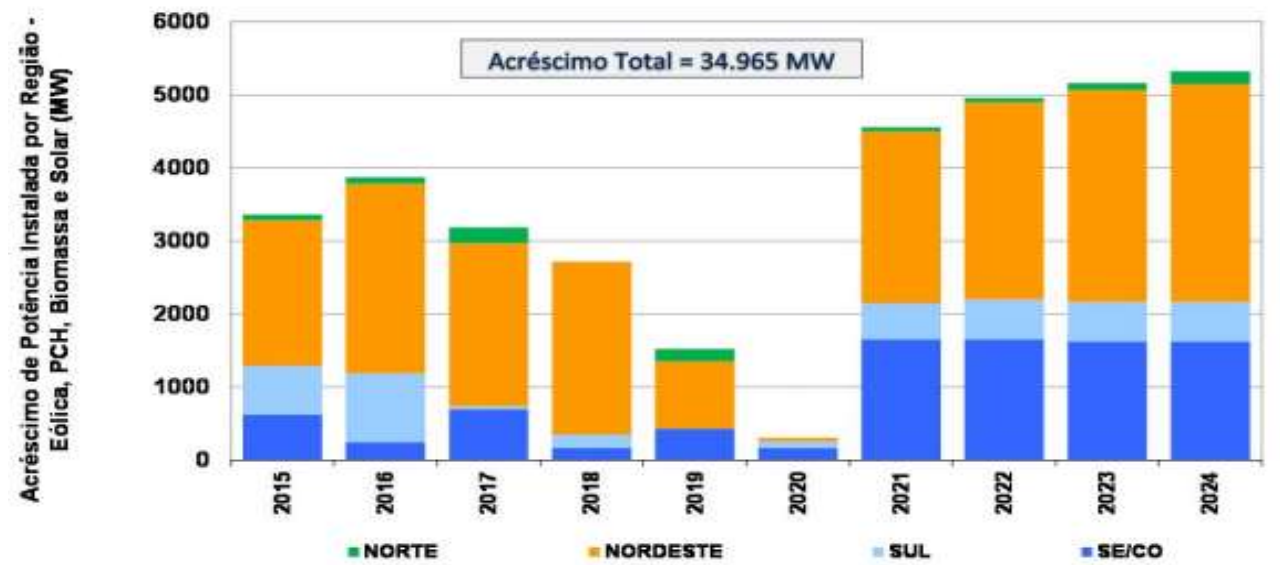

Gráfico 1 - Acréscimo de capacidade instalada de eólica, PCH e biomassa. Fonte: EPE (2015).

O crescimento de grandes empresas de fabricação de aerogeradores com participação no setor demonstra a atratividade desse mercado. A consultoria norte-americana Ernst \& Young publicou em novembro de 2011 um índice de atratividade do mercado de energias renováveis de diversos países, onde o Brasil apareceu como 10 país mais atrativo para investimentos em energias renováveis e 9o mercado mais atrativo para investimento em energia eólica. Esse fato deveu-se, entre outros, o fato da crise de 2008-2009 ter desaquecido mercados tradicionais na Europa e na América do Norte fazendo com que empresas internacionais voltassem-se para mercados emergentes, como o Brasil. Dessa forma, a rapidez do crescimento do setor eólico brasileiro e de novas fábricas no país tornou-se necessário a discussão dos efeitos 
sociais e econômicos que esse crescimento acelerado da energia eólica irá trazer à economia brasileira (SIMAS et al., 2013).

Existem aspectos socioambientais diretamente associados a atividade de energia eólica que merecem destaque, apesar dos baixos impactos relacionados a ela. A Resolução no 462/2014, do Conselho Nacional do Meio Ambiente (CONAMA), que estabelece procedimentos para o licenciamento ambiental de empreendimentos de geração de energia elétrica a partir de fonte eólica em superfície terrestre, contempla as questões ambientais mais relevantes. Segundo o EPE (2015), o empreendimento não será considerado de baixo impacto se estiver localizado em:

\begin{abstract}
áreas regulares de rota, pousio, descanso, alimentação e reprodução de aves migratórias, constantes no Relatório Anual de Rotas e Áreas de Concentração de Aves Migratórias no Brasil; formações dunares; bioma Mata Atlantica e implicar cortes e supressão vegetal; zona Costeira e implicar alterações significativas das suas características naturais; locais que provoquem Plano Decenal de Expansão de Energia 2024 - Análise Socioambiental 404 Ministério de Minas e Energia Empresa de Pesquisa Energética impactos socioculturais diretos; e áreas de ocorrência de espécies ameaçadas de extinção e áreas de endemismo restrito, conforme lista oficial. Nesses casos, as licenças requerem a apresentação de Estudo de Impacto Ambiental e Relatório de Impacto Ambiental (EIA/Rima), ao invés do RAS (Relatório Ambiental Simplificado).
\end{abstract}

No PDE 2024 estima-se a criação de 141 mil vagas de trabalho, que para cada MW eólico instalado sejam geradas 7,5 vagas de trabalho ao ano [248], em especial na fase de construção dos parques (EPE, 2015). Nos últimos tempos, vários estudos foram realizados para avaliar os efeitos econômicos e ambientais da utilização das energias renováveis, especialmente em relação à redução das emissões de GEE dos sistemas energéticos e os efeitos das políticas climáticas na economia. Este estudo pretende demonstrar as etapas necessárias que uma empresa de geração de energia eólica precisa realizar para produção de energia elétrica a partir da fonte de energia eólica.

\title{
Etapas para Produção de Energia Elétrica a partir da Fonte de Energia Eólica
}

Em uma torre eólica, o vento gira uma hélice conectada ao aerogerador, que produz eletricidade. Tem-se um parque eólico quando há vários mecanismos como esse, ligados a uma central de transmissão de energia. Entretanto, a sua instalação é um processo que necessita de profissionais de várias áreas como engenheiros na área civil, mecânica, elétrica, ambiental, entre outros (ELOI, 2012). Adiante, busca-se descrever as etapas para implantação de uma usina eólica.

\section{Definir a área de instalação e análise do potencial eólico desse local}

A primeira etapa inicia-se com a definição da área de instalação e análise do potencial eólico desse local (ELOI, 2012). Deve-se observar três fatores: 1) Caracterização da área - deve-se ter a planta de localização da área; 2) Parecer Ambiental - É necessário o conhecimento prévio de que a área disponibiliza esteja em consonância com o permitido com as disposições ambientais. O Parecer Ambiental deve expor a caracterização ambiental da área quanto à geomorfologia, solos, geologia, recursos hídricos, uso e ocupação do solo. Também é necessário ter o conhecimento sobre o enquadramento legal da área;3) Enquadramento 
municipal - Deve-se ter uma declaração do Município anuindo a conformidade com o plano diretor para o uso e ocupação do solo no que concerne empreendimentos de energia renovável (ARAÚJO, 2009).

A realização de uma pesquisa do entorno técnico poderá identificar os projetos em desenvolvimento no entorno da área disponibilizada para estudo e desenvolvimento do parque eólico. Os efeitos de vizinhança associados aos efeitos de esteira do parque poderão ocasionar resultados danosos não previstos no projeto (ARAÚJO, 2009).

\section{Identificar a potência do vento}

É interessante que se pesquise locais com médias de velocidades de vento altas, e também se analise a melhor altura da torre sobre a qual o aerogerador será instalado, pois a velocidade do vento aumenta com a altura. O Brasil, apesar de possuir uma grande extensão territorial, deve analisar os projetos eólicos a fim de fazer um melhor aproveitamento do território desde o início da exploração dos ventos (DALMAZ et al., 2008).

\section{Aproveitamento da potência instalada em um parque eólico}

Segundo Dalmaz et al. (2008) vários fatores influenciam a eficiência de um aerogerador e de um projeto eólico, entre eles, aerodinâmicos, que também dependem do projeto das pás do aerogerador, e a variabilidade da velocidade e direção dos ventos. Portanto, mesmo para locais com excelentes médias de velocidade de vento, o aerogerador estará operando, na maior parte do tempo, com uma potência menor que sua potência nominal, ou seja, em carga parcial. O Fator de Capacidade (FC) é uma maneira de se avaliar a capacidade de geração de um parque eólico, o qual pode ser calculado a partir da equação adiante:

$$
F C=\frac{E_{a}}{P_{N}{ }^{T}}
$$

Onde $E_{a}$ é a quantidade de energia produzida no intervalo de tempo $T$, e $P_{N}$ é a soma das potências nominais dos aerogeradores do parque eólico. Representa a quantidade de energia que seria gerada caso a velocidade do vento estivesse sempre acima da velocidade nominal. Quando o FC dá acima de 0,3, ele é considerado um bom resultado, ou seja, significa dizer que se está aproveitando $30 \%$ do potencial instalado ou mais, dependendo do resultado. O FC representa um importante critério de decisão de escolha da viabilidade técnica e econômica da usina. É um indicador da produção energética e consequentemente do potencial de instalação de turbinas eólicas em um local. Diferentes locais (estações) usando o mesmo modelo de turbina apresenta diferentes fatores de capacidade, função da velocidade média dos ventos (FÁDIGAS, 2013). Vale salientar, que:

Um empreendimento eólico está sujeito aos caprichos da natureza, de forma que mesmo tendo-se uma grande potência instalada nenhuma energia será gerada, quando os ventos forem fracos. Desta forma, uma matriz energética dependente da geração eólica tornaria o sistema de energia elétrica bastante vulnerável. Esta preocupação em relação à inconstância da produção de energia pelos aerogeradores, devido às variações na 
velocidade do vento, torna-se cada vez mais importante, à medida que aumenta a participação da geração eólica na matriz energética dos países (DALMAZ et al., 2008).

\section{Previsão de ventos e de geração eólica de energia}

Diante do exposto anteriormente, percebe-se que as características tornam a energia eólica menos competitiva em relação às outras formas de geração, como a hidráulica e a térmica, pois para que se tenha um suprimento seguro e viável de energia, a sua quantidade deve ser suficiente para atender à demanda com a menor incerteza possível.

A fim de permitir que a energia eólica contribua de forma complementar à matriz energética, torna-se fundamental uma previsão precisa da velocidade e da direção do vento, no local do parque eólico. Esta previsão pode ser feita por um modelo numérico de previsão meteorológica (NWP) baseado nas equações da mecânica dos fluidos, que descrevem teoricamente o comportamento do ar atmosférico em escoamento. No entanto, as previsões dos modelos NWP são para áreas bem maiores que a área ocupada por um parque eólico, portanto com uma resolução relativamente baixa. (DALMAZ et al., 2008).

Após a definição do local de instalação, é feita a medição dos ventos por um período de no mínimo 24 (vinte e quatro meses). Medições com qualidade são consideradas de um período entre 5 e 10 anos. Para usar medidas de ventos feitas em um curto espaço de tempo, faz-se necessária a correlação dos dados de vento com medições de longo prazo realizadas em outros locais. Este procedimento chama-se MCP - Medir, Correlacionar, Prever (FÁDIGAS, 2013). A Certificação de Medições Anemométricas deverá atender obrigatoriamente aos seguintes requisitos (EPE, 2014):

a) Ter por base um período de medições anemométricas, conforme disposto nas Portarias MME no 21, 18/01/2008, e MME no 29, de 28/01/2011, devendo ser informados o início e o fim do período de aquisição dos dados;

b) As medições anemométricas e climatológicas deverão ser realizadas numa região próxima ao local do parque eólico, definido conforme o § 1ㅇdo art. 6ㅇ-A, da Portaria MME $\mathrm{n}$ ㅇ $21 / 2008$.

c) As medições deverão ser feitas em pelo menos duas alturas distintas, sendo uma a partir de 50 metros, por período não inferior a 24 (vinte e quatro) meses consecutivos, sempre iniciado a partir de dados válidos, devendo ser integralizadas a cada 10 (dez) minutos e ter uma taxa de perda de dados inferior a $10 \%$ (dez por cento), destacando-se que o período contínuo de ausência de medições não poderá superar 15 (quinze) dias;

d) Deverão ser informadas a taxa de perda de dados e a metodologia empregada para o preenchimento das perdas dos dados medidos;

e) Informações sobre os dados de temperatura, densidade média anual do ar, pressão atmosférica no local do parque eólico, incluindo identificação e localização das estações meteorológicas de origem dos dados, quando não medidos em instrumentos da torre anemométrica em estudo;

f) Médias mensais de longo prazo da velocidade do vento e os respectivos parâmetros (fator de forma e fator de escala) da distribuição de Weibull, para cada mês, extrapoladas à elevação (altura) do rotor da turbina;

OBS.: esses dados deverão ser informados na Guia "Características Técnicas/Dados Anemométricos Certificados" do AEGE.

g) Rosa dos Ventos, com 16 setores2, apresentada também, em forma de tabela, explicitando os percentuais de permanência em cada setor, conforme modelo do ANEXO V;

h) Velocidade de referência (Vref, 50 anos, 10 minutos), rajada máxima (Ve50, 50 anos, 3 segundos), intensidade de turbulência média $(\mathrm{V}>4 \mathrm{~m} / \mathrm{s})$, intensidade de turbulência 
Normal (quantil de $90 \%$ ) e classe IEC do parque eólico, conforme NBR-6123/1988 e IEC61400-3a edição; e

i) Os arquivos digitais em formato "Excel" com as medições anemométricas contendo dados brutos e dados tratados devem ser gravados no Anexo 6 -

Certificado, conforme descrito na tabela do ANEXO VII.

Sem prejuízo aos requisitos descritos acima, que se aplicam exclusivamente para fins de cadastramento e habilitação técnica, os empreendedores que se sagrarem vencedores nos leilões de energia deverão iniciar medições anemométricas e climatológicas permanentes no local do parque de geração, em conformidade com a Portaria MME no 29, de 28 de janeiro de 2011. Essas medições deverão cumprir os requisitos especificados na Nota Técnica da EPE, "INSTRUÇÕES PARA AS MEDIÇÕES ANEMOMÉTRICAS E CLIMATOLÓGICAS EM PARQUES EÓLICOS".

Assim, é possível estabelecer uma velocidade média anual para a geração de energia elétrica. “Além da velocidade dos ventos, é importante que eles sejam regulares, não sofram turbulências e nem estejam sujeitos a fenômenos climáticos como tufões" (ELOI, 2012).

A instalação de torres de medição meteorológicas deverá ser feita em três níveis de medição e deverão conter instrumentos necessários para a colheita e compilação dos dados de ventos, direção do vento, umidade relativa, pressão atmosférica e temperatura (ARAÚJO,2009).

\section{Identificar condições tipográficas e de vegetação}

Visando garantir a viabilidade do parque eólico, as condições tipográficas e de vegetação devem ser observadas na primeira etapa do projeto. "A topografia deve ser realizada para a área disponibilizada para os estudos e ser devidamente associada a topografia do entorno (diâmetro de $40 \mathrm{~km}$ ). O Datum é o SIRGAS 2000" (ARAÚJO, 2009).

Em relação ao meio ambiente, o autor citado anteriormente saliente que se deve realizar estudos ambientais requeridos para o empreendimento (RAS/IEA), os quais deve levar em consideração a área de influência; o conhecimento geológico da área; as unidades geoambientais, (dunas, área antropizada, planície de deflação, alagados etc.); solos, uso do solo e cobertura vegetal; Declividades; Área de Preservação Permanente (APP), Área de Proteção Ambiental (APA) e Associação do Patrimônio Natural (APN).

\section{Elaborar o projeto de Micrositing}

Após a definição do potencial eólico e da área definidos, segue-se para outra etapa, a elaboração do projeto de Micrositing. A Estimativa do potencial eólico em cada gerador na área do parque eólico, "também conhecido como estudos de Micrositing, consiste em determinar as características do vento em toda a área da fazenda eólica, de forma a estimar a produção de energia em cada um dos aerogeradores" (FÁDIGAS, 2013). Ainda segundo a autora anterior, o Projeto Micrositing define o exato posicionamento de cada aerogerador na Usina Eólica, objetiva maximizar a Produção Anual de Energia (PAE) e alteração do posicionamento implica em alteração da Produção Anual de Energia. No projeto devem constar o layout da usina, tipo de máquina, fabricante, altura das torres, potência, previsão de geração anual de energia e a capacidade máxima de produção (ELOI, 2012). 
Nessa fase, também são realizados estudos do solo e infraestrutura para o abastecimento da energia, no que diz respeito à distância até a subestação mais próxima e ao plano logístico para a distribuição da eletricidade gerada. $O$ projeto também deve incluir um estudo ambiental e socioeconômico, de maneira que a usina ofereça o menor impacto possível à região. Além disso, a área deve estar regularizada e com as respectivas licenças ambientais em dia (ELOI, 2012).

Segundo Araújo (2009), "a reunião de todas as informações coletadas e ou desenvolvidas durante o prazo de estudos deverão ser compiladas resultando no micrositing ideal”. A figura adiante demonstra um exemplo simplificado dessas informações.

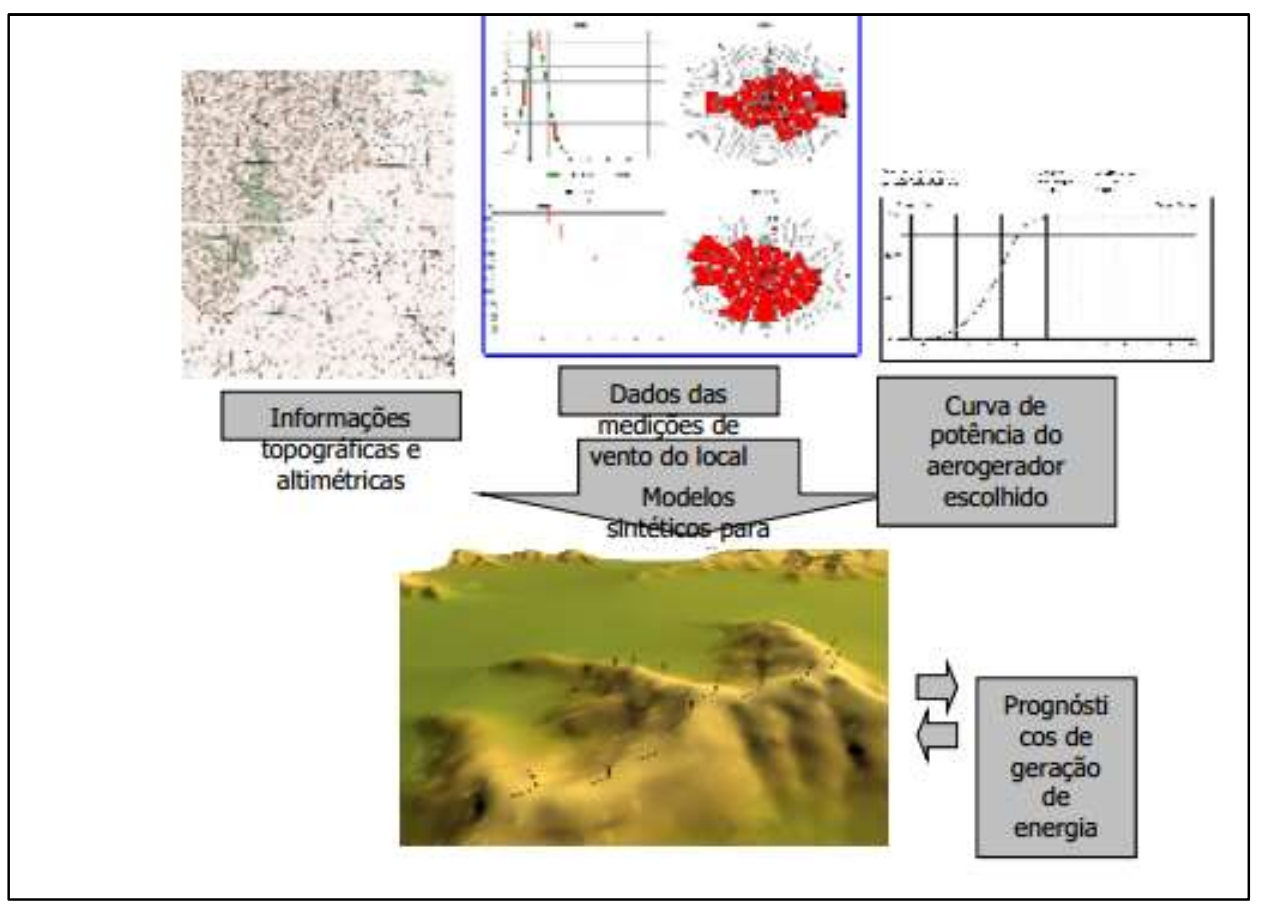

Figura 1: Reunião de todas as informações coletadas e ou desenvolvidas durante o prazo de estudos. Fonte: Araújo (2009).

\section{Definir o tipo de aerogerador}

Após o término do projeto Micrositing é feita a escolha do aerogerador, visto que a quantidade de energia produzida por uma turbina varia de acordo com o tamanho das suas hélices e com o regime de ventos da região. Depois dessas etapas é que se torna possível conhecer a viabilidade técnica e comercial do parque (ELOI, 2012). Adiante, será discutida a instalação do parque eólico e do processo de instalação dos aerogeradores que compõem uma usina.

\section{Instalação}

Após a aprovação do projeto, a instalação dos equipamentos necessários ao seu funcionamento é realizada pela empresa responsável pelo parque. A limpeza do terreno e a terraplanagem do local, com nivelamento e pavimentação dos acessos aos aerogeradores deve ser realizada antes de tudo. Logo após e realizado o estaqueamento, que consiste na colocação de estacas nas bases dos aerogeradores para sua interligação ao solo, as quais serão, posteriormente, incorporadas ao bloco da fundação, dando sustentação à torre do aerogerador, posteriormente, a empresa dá início à concretagem da base dos aerogeradores. A 
concretagem acontece em três etapas: montagem das ferragens; montagem das conexões elétricas e civis necessárias para a transmissão de energia; e, por fim, a concretagem da base, que requer, aproximadamente, 50 caminhões de concreto por torre (ELOI, 2012).

Ainda segundo o autor anterior, terminada a cura do concreto, dá-se início à montagem das torres, que são divididas em blocos sobrepostos. No mesmo período da montagem das torres, também ocorre a montagem das subestações unitárias, de transição e principal, da usina. Após essa etapa, é realizada a interligação elétrica dos aerogeradores com as subestações através de cabos subterrâneos. Nessa fase, também são montadas as linhas de transmissão aéreas, interligando os parques à subestação coletora.

Com a torre erguida, chega a hora de instalar a nacele, suporte onde fica o gerador e o sistema de transmissão de energia.

O gerador é então montado. Essa é uma das fases mais complicadas do processo, pois é preciso ter as condições atmosféricas ideais. Ventos muito fortes, por exemplo, impossibilitam a instalação.

Uma vez montado, chega a hora de conectar as pás ao aerogerador. Para chegar até o parque, essas pás gigantes, de 49 metros de comprimento, são transportadas por supercaminhões.

Por fim, o aerogerador é concluído.

Mas, antes de começar a funcionar efetivamente, cada turbina precisa passar por testes e verificações de tensão e produção de eletricidade.

Durante toda a etapa de edificação dos aerogeradores, vários profissionais são envolvidos no processo. Entre eles: operários, caminhoneiros, profissionais de logística e engenheiros mecânicos e elétricos (ELOI, 2012).

Adiante se pode observar uma foto aérea tirada no Parque Eólico de Caetité na Bahia, atualmente em funcionamento, onde a esquerda (em vermelho e branco) encontra-se uma torre anemométrica instalada a aproximadamente 8 anos (desde 2008) e a esquerda aerogeradores Modelo GE 1.68-82.5.

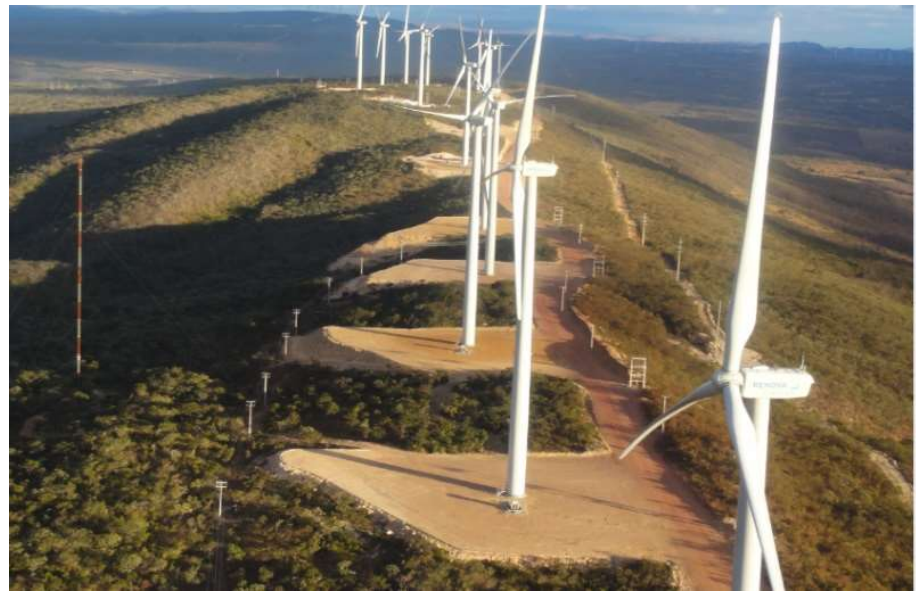

Figura 3: Parque eólico de Caetité/BA .

\section{Funcionamento}

O funcionamento de um parque eólico inicia-se com a criação e aprovação do projeto. Após a proposta aprovada, é dado início à instalação das turbinas, as quais gerarão eletricidade. Realizados alguns testes, as turbinas começam a funcionar, efetivamente. Os aerogeradores geram energia elétrica a partir do vento. Onde Os cata-ventos gigantes são os grandes protagonistas de uma usina eólica. Como exemplo cita- 
se o Complexo Eólico Trairi, onde serão instalados 50 aerogeradores modelo SWT-2.3-101, de gerador assíncrono, torres de 80 metros e rotor horizontal de três pás. São essas pás que capturam a energia cinética do vento e a transformam em energia rotacional. Vislumbrando um maior entendimento como elas giram e produzem eletricidade, veja a figura adiante (ELOI, 2012).

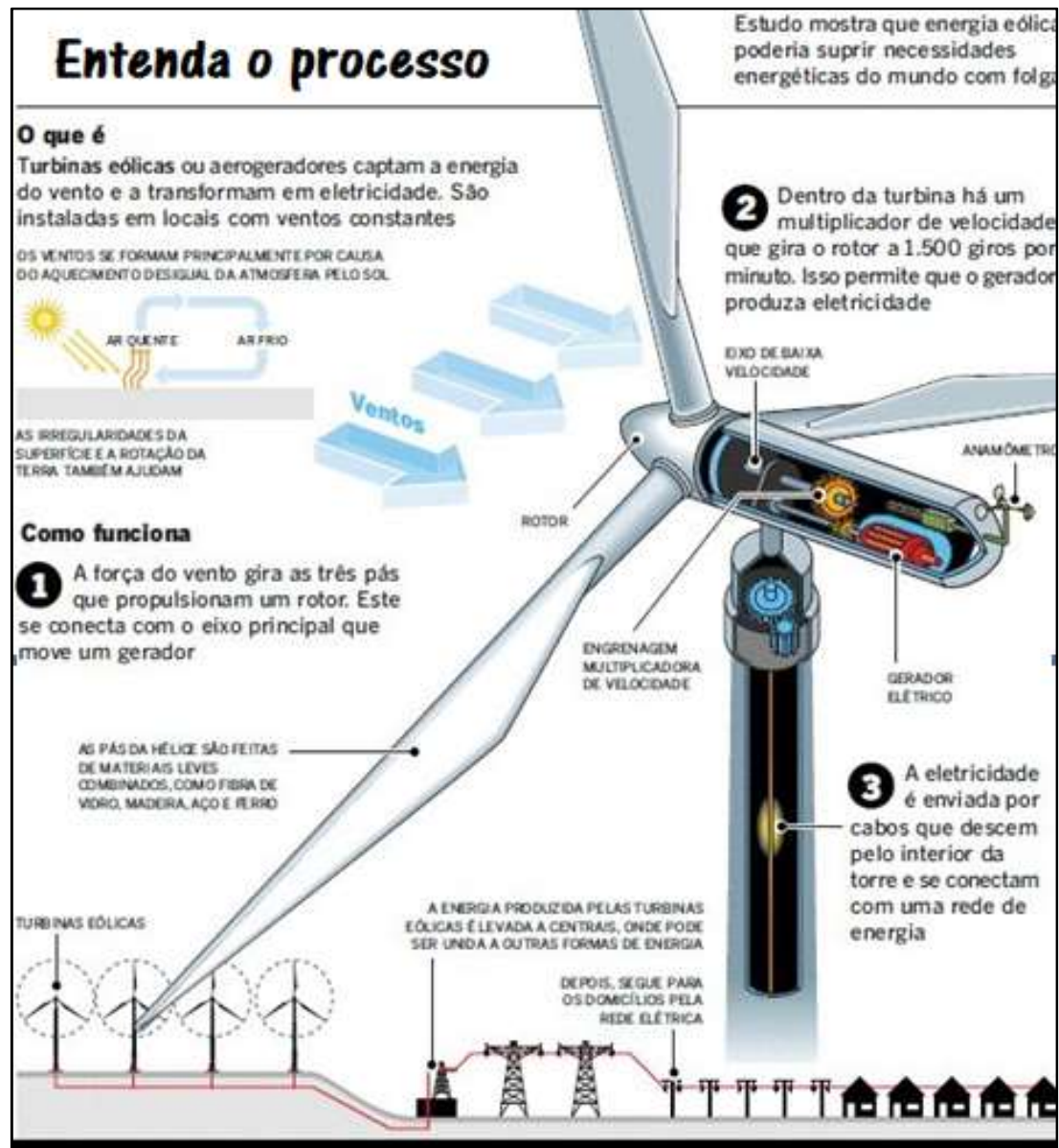

Figura 4: Identificação de como os aerogeradores geram energia elétrica a partir do vento. Fonte: Eloi (2012).

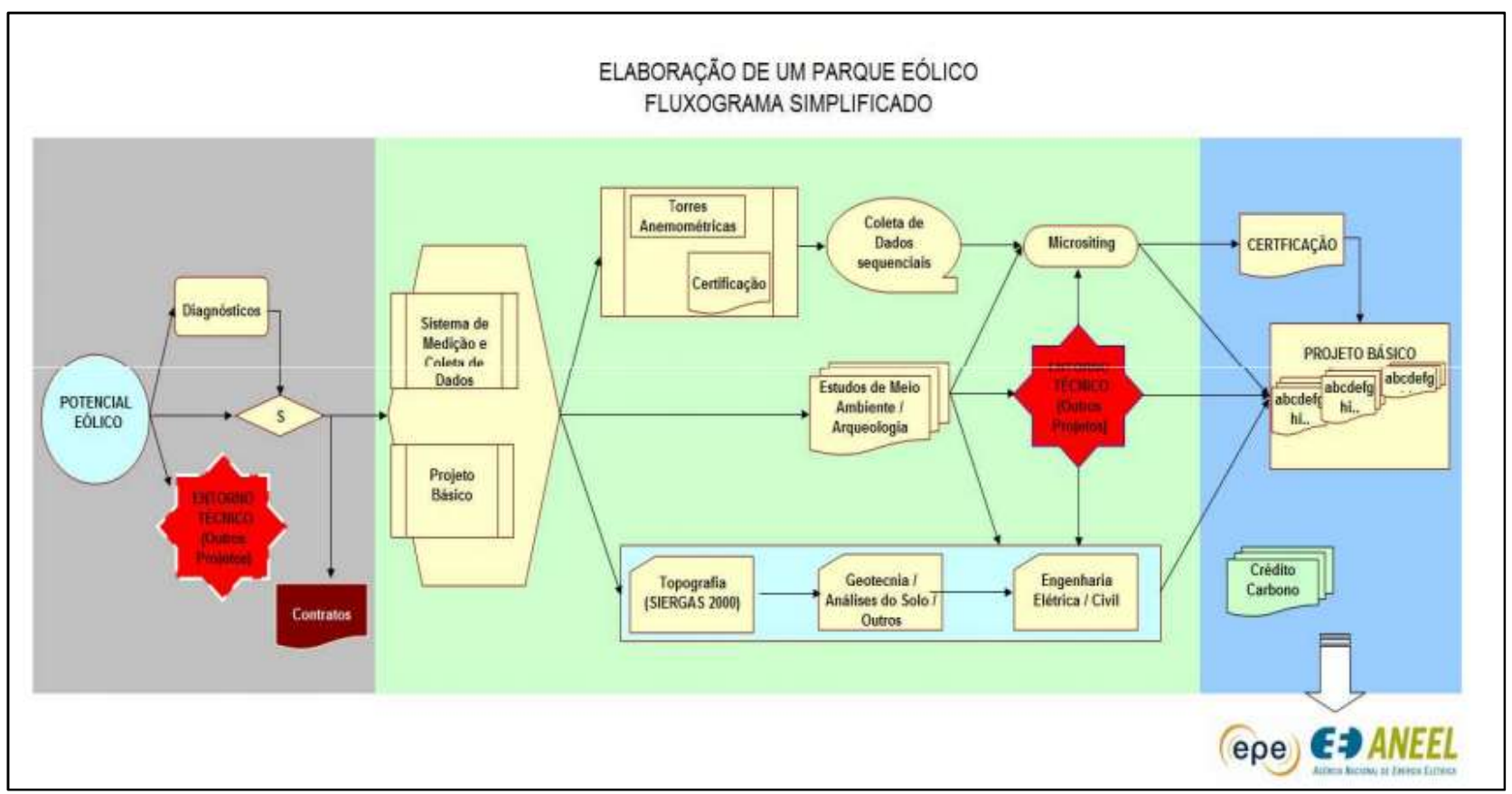

Figura 5: Fluxograma simplificado de elaboração de um parque eólico. Fonte: Araújo (2009). 
Na Figura 05 apresenta-se um fluxograma simplificado de elaboração de um parque eólico. Fádigas (2013), diz que algumas incertezas na produção de energia são resultado da combinação das seguintes fontes de incerteza:

Incertezas na velocidade do vento: medição, extrapolação vertical e horizontal e climatologia. A partir de uma análise de sensibilidade da variação na velocidade do vento $\mathrm{e}$ a consequente variação na produção de energia, as incertezas na velocidade do vento podem ser convertidas em incertezas de geração.

Incerteza na curva de potência da turbina: calculada durante os ensaios de medição da curva, englobando as incertezas estatísticas e as do sistema e da instrumentação.

Incertezas no cálculo das perdas aerodinâmicas do parque, que decorre do modelo de interferência aerodinâmica utilizado entre turbinas.

\section{CONSIDERAÇÕES FINAIS}

A geração de energia eólica vem passando por um crescimento acelerado no Brasil. Desde 1992, com a instalação do primeiro aerogerador no Brasil, houve um avanço regulatório no país com a inclusão de políticas de incentivo para o avanço dessa tecnologia, hoje considerada uma alternativa energética, limpa e competitiva. Grandes empresas instalaram-se no Brasil, mais precisamente após a crise financeira de 20082009 que desaqueceu mercados na Europa e na América fazendo com que as mesmas procurassem mercados emergentes, como o Brasil. Desta forma, o mercado nessa área passou a ser mais diversificado e com maior concorrência.

O crescimento de energia eólica citado anteriormente trouxe diversos benefícios regionais os quais contribuíram para o desenvolvimento sustentável no Brasil, principalmente em locais pouco desenvolvidos, a exemplo da Bahia e do Rio Grande do Norte, os quais tiveram grandes projetos contratados que serão construídos nos próximos anos.

Percebe-se que, principalmente, devido ao desenvolvimento tecnológico e de políticas públicas de incentivo recentes, como também a questão ambiental e a experiência operativa acumulada nos últimos anos em todo o mundo, há um aumento da participação dessas fontes renováveis na matriz energética nacional.

Segundo a EPE (2013), a competitividade apresentada nos últimos leilões de oferta de energia mostrou a possibilidade da inserção de fontes renováveis de energia na matriz elétrica brasileira, mesmo que o atual estágio de desenvolvimento dessas tecnologias ainda possibilite ganhos de produtividade e de escala além de melhorias no desempenho técnico-econômico no Brasil.

Políticas e projetos que objetivam a promoção da utilização de outras fontes renováveis já estão sendo incorporados às políticas tecnológicas, ambiental e energética Brasileira, as quais beneficiam o país de várias formas, como por exemplo a ampliação do conhecimento técnico e do número de empregos; redução do custo de produção de eletricidade; aumento da oferta de energia com redução dos impactos socioambientais; redução da emissão de GEE, e; fornecimento de energia sustentável a longo prazo (EPE, 2013).

Diante do que foi exposto, percebeu-se a importância do aumento de participação de fontes renováveis de geração de energia elétrica, entre elas, a eólica. Portanto, o presente trabalho apresentou as 
etapas necessárias para implantação de um parque eólico, buscando, sempre, demonstrar a importância da geração de energia elétrica através da fonte de energia eólica visto que o Brasil ainda produz pouca energia a partir desta fonte, apesar de possuir um vasto território com um vasto potencial para a produção da mesma.

\section{REFERÊNCIAS}

ARAÚJO, M. D.. Empresa Potiguar a Serviço da Energia Eólica. Fórum Nacional Eólico, 2009.

BARBOSA, G. S.. O Desafio Do Desenvolvimento Sustentável. Revista Visões, v.1, n.4, 2008.

BARBOSA, A. C. L.. Avaliação Ambiental do Uso da Energia Eólica Para Usuários de Pequeno Porte. Monografia (Graduação em Administração) - Universidade Federal do Rio Grande do Sul, Porto Alegre, 2008.

BERMANN, C.. Crise ambiental e as energias renováveis. Revista Ciência e Cultura, v.60, n.3, p.20-29, 2008.

LONGARAY, A. A.; RAUPP, F. M.; SOUSA, M. A. B.; COLAUTO, R. D.; PORTON, R. A. B.; BEUREN, I. M.. Como Elaborar Trabalhos Monográficos em Contabilidade. São Paulo: Atlas, 2008.

CASTRO, R.. Energias renováveis e produção descentralizada, introdução à energia eólica. 2003.

CEPEL. Atlas do Potencial Eólico Brasileiro. 2001.

CMMAD. Comissão Mundial sobre Meio Ambiente e Desenvolvimento. Nosso Futuro Comum. 2 ed. Rio de Janeiro: FGV, 1991.

DALMAZ, A.; PASSOS, J. C.; COLLE, S.. Energia eólica para geração de eletricidade e a importância da previsão. Revista ABCM - Engenharia, v.13, n.1, 2008

ELOI, G.. Etapas da construção de um parque eólico. 2012.
EPE. Plano Decenal de expansão de energia 2024. Empresa de Pesquisa Energética, 2015.

EPE. Expansão da Geração: Empreendimentos Eólicos: Instruções para Solicitação de Cadastramento e Habilitação Técnica com vistas à participação nos Leilões de Energia Elétrica. No EPE-DEE-017/2009-r11. 2014.

FÁDIGAS, E. A. F. A.. PEA 5002: Energia Eólica: Fundamentos e Viabilidade Técnico-Econômica. São Paulo, 2013.

IPCC. Special report on renewable energy Sources and Climate Change Mitigation. 2011.

LOPES, A. M.. Produção Eólica e Enquadramento TécnicoEconómico em Portugal. Dissertação (Mestrado Integrado em Engenharia Electrotécnica e de Computadores) - Major Energia, 2009.

NAGATA, M.; VIEIRA, M. A.; SILVA, R. R. S.. Desenvolvimento Sustentável e Responsabilidade Social Corporativa: É possível ser sustentável?: Caso MAPFRE S.A.. 2010.

ROSA, V. H. S.. Energia elétrica renovável em pequenas comunidades no Brasil: em Busca De Um Modelo Sustentável. Tese (Doutorado em Desenvolvimento Sustentável) - Universidade de Brasília, Brasília, 2007.

SIMAS, M.; PACCA, S.. Energia eólica, geração de empregos e desenvolvimento sustentável. Estudos Avançados, v.27, n.77, 2013. 